\title{
Simulation of fish population responses to exploitation
}

\author{
A.L. Jensen \\ School of Natural Resources, University of Michigan, Ann Arbor, MI 48109-1115, USA
}

(Accepted 3 October 1990)

\section{ABSTRACT}

Jensen, A.L., 1991. Simulation of fish population responses to exploitation. Ecol. Modelling, 55: $203-218$.

A model that couples Larkin's predator-prey model, Ivlev's feeding model, Ursin's growth equation and the exponential mortality model was applied for simulation of the responses of fish populations to exploitation. Simulations were done without food-limited growth, with food-limited growth, with food limited growth and size-specific mortality, and with foodlimited growth and age at maturity a function of size. Without food-limited growth there was no compensation for exploitation and the population became extinct with an increase in mortality. With food-limited growth the population compensated for fishing mortality; as abundance decreased, size increased, and production of eggs by the population increased. With either mortality or age at maturity a function of size, compensation was much higher than with food-limited growth alone. Recruitment decreased with increase in exploitation. There was an association between numbers of spawners and recruits, but both the number of spawners and the number of recruits were determined by food limited growth. If age at maturity is a function of size, there are fluctuations in population abundance when fishing mortality is low, but not when fishing mortality is high.

\section{INTRODUCTION}

For conservation of fishieries, it is necessary to understand the responses of fish populations to exploitation. Many authors have reported that compensation for fishing occurs through increased survival of young and a decrease in age at maturity. Studies of both exploited fish populations (Beverton and Holt, 1957; Jensen, 1971; Cushing, 1975; Ricker, 1975; Healey, 1980) and laboratory fish populations (Silliman and Gutsell, 1958; Silliman, 1968, 1971; Dahlgren, 1979; Hankin, 1980) indicate that compensation for fishing occurs through increased fecundity, a decrease in age at maturity, or increased survival of young. The net reproductive rate was applied to show that only survival of young and age at maturity had the 
capacity to compensate for large increases in mortality (Jensen, 1981). Components of a bioenergetic life history model were applied to determine the capacity of changes in life history parameters to compensate for increases in mortality, and again it was indicated that survival of young and age at maturity were the most important factors (Jensen, 1989).

The connection between fishing mortality, age at maturity, and survival of young has not been clearly established, but one of the most remarkable features of fish is their high variation in growth which is inversely related to abundance. It often has been suggested that survival of larvae and age at maturity are related to the available food resource. A high density of fish that results in a shortage of food would rarely results in starvation (Ivlev, 1961), but it can result in both poor condition and smaller sizes. Poor condition could result in lower lipid concentrations, fewer spawnings, a smaller number of gametes per gram of fish, lower nutrient levels in gametes, poorer condition of larvae, and a smaller percentage females (Hjort, 1914; Beverton and Holt, 1957; Ricker, 1975; Rothschild, 1986; Saila et al., 1987). A smaller size could result in fewer eggs per individual, older age at maturity, and a higher rate of predation.

Parameters are difficult to estimate for models in which limited food resources result in poor condition, but most parameter estimates are readily available for models in which a limited food resource results in smaller sized individuals. Therefore, a model was developed and applied for simulation of population growth where ration was related to population abundance, growth was related to ration, and number of eggs per $\mathrm{kg}$ female was constant. Simulations were done with growth not dependent on ration, growth dependent on ration and fixed age specific mortalities, growth dependent on ration and mortality dependent on size, and growth dependent on ration and age at maturity a function of size. The objectives were to determine if such relations would enable a population to survive exploitation and attain a stable new population level, and, if this occurred, to examine the relations generated between fishing mortality and yield, fishing mortality and recruitment, and stock size and recruitment.

The model was applied using data for the walleye (Stizostedion vitreum) population in the western basin of Lake Erie, but some parameters were estimated with data for other walleye populations. The walleye population of Lake Erie is of interest because it is of significant commercial and sport value, and well documented changes in abundance and growth have occurred during the past 15 years (Muth and Wolfert, 1986).

THE MODEL

Simple, well established relations among food abundance, growth, and mortality were applied. Most of the components of the model are the same 
as those applied by Jensen (1989), but a new component was added for age at maturity, and the components were coupled. The model combines Larkin's (1956) predator-prey model, Ursin's (1967) bioenergetic growth model, Ivlev's (1961) feeding model, the exponential mortality model, and the relation between mortality and size developed by Peterson and Wroblewski (1984).

Each year in the simulations was separated into four different time periods to describe the changing composition of the population during a year. During the winter the population consisted of juveniles and adults, and each age was simulated separately. Egg production occurred in the spring, starting the second time period. After the eggs hatched the third time period began, and the population consisted of larvae, juveniles, and adults. Later, in the fourth time period, after the larvae had become young of year, YOY, the population consisted of YOY, juveniles, and adults. Changes in the population and food concentration were calculated each day. At the end of 365 days, ages were incremented by one year.

Eggs are spawned in the spring; the number of eggs produced is:

$H \sum_{i=x_{m}}^{x_{r}} N(x) W(x) / 2$

where $H$ is the average number of eggs per gram of female, $N(x)$ is the abundance of age $x$ individuals in the population at the time of spawning, and $W(x)$ is the weight of age $x$ individuals. The number of larvae hatching after the incubation period is $s E$, where $E$ is the number of eggs and $s$ is the egg survival rate.

The relation between predator abundance and prey abundance has been described with many different equations; for fish populations Larkin (1966) concluded that the classical equations of Lotka and Volterra do not apply because they indicate starvation of a predator when a prey species becomes extinct. At equilibrium the equations Larkin (1966) recommended become: $N_{1}=K_{1}-b_{1} K_{1} N_{2} / r_{1}$

where $N_{1}$ is prey density, $N_{2}$ is walleye density, $r_{1}$ is the prey population growth coefficient, $K_{1}$ is prey density at the carrying capacity, and $b_{1}$ measures the impact of predators on prey abundance.

Growth was modelled using a bioenergetic growth model that combines the works of Winberg (1956), Ursin (1967) and Ivlev (1961). Based on Winberg's (1956) energy balance equation, Ursin (1967) proposed modelling growth as:

$\mathrm{d} W / \mathrm{d} x=e_{\mathrm{f}} \mathrm{d} R / \mathrm{r} x-Q$

where $\mathrm{d} W / \mathrm{d} x$ is the growth rate $\left(\right.$ cal g $\left.^{-1} \mathrm{day}^{-1}\right), \mathrm{d} R / \mathrm{d} x$ is ration (cal $\mathrm{g}^{-1}$ 
day $\left.^{-1}\right), Q$ is the total metabolic rate $\left(\mathrm{cal} \mathrm{g}^{-1} \mathrm{day}^{-1}\right)$, and $e_{\mathrm{f}}$ is the efficiency of food utilization. Ursin (1967) modelled the rate of food consumption as: $\mathrm{d} R / \mathrm{d} x=b_{0}(1-A f) f h W^{m}$

where $b_{0}(1-A f)$ is the amount of food absorbed, which depends on the feeding level, $f$ is the feeding level, $0 \leq f \leq 1$, and $h$ is a coefficient of food consumption and $b_{0}$ and $A$ are parameters. The rate of metabolism was separated into two components - feeding catabolism and fasting catabolism (Ursin, 1979):

$Q=a \mathrm{~d} R / \mathrm{d} x+k W^{n}$

where $a$ and $k$ are parameters.

The feeding level was a function of prey abundance, and based on Ivlev's (1961) equation:

$f=1-\exp \left(-S N_{1}\right)$

where $N_{1}$ was prey density and $S$ was a coefficient. For simplicity, it was assumed that some constant fraction $b$ of the food ingested was absorbed, then the growth equation became:

$\mathrm{d} W / \mathrm{d} x=C\left[1-\exp \left(-S N_{1}\right)\right] W^{m}-k W^{n}$

where

$C=(1-a) b h$

Mortality was modeled with the exponential model:

$N(x)=N\left(x_{0}\right) \exp \left[-Z\left(x-x_{0}\right)\right]$

where $N(x)$ was abundance at age $x, x_{0}$ was the initial age, and $Z$ was the instantaneous mortality coefficient. Mortality coefficients were dependent on age or size.

In simulations where age at maturity was dependent on size, the distribution of weights at a given age was described using the logistic probability distribution because its shape is similar to the normal distribution and its distribution function:

$F(x)=1-\{1+\exp [(W(x)-a) / k]\}^{-1}$

can be found in closed form. In equation (9) the mean weight is $a$, and the variance of weight is $k^{2} \pi^{2} / 3$. The proportion of each age group larger than the weight at maturity was calculated at the time of spawning. In the

$\overline{\text { cal, calorie }}($ International Table $)=4.1868 \mathrm{~J}(\mathrm{def})$. 
simulations, each day the feeding level was calculated, then the amount of growth was calculated, and then abundance was calculated.

\section{PARAMETER ESTIMATION}

The model was applied to the walleye population of the western basin of Lake Erie, and most of the parameter estimates are the same as in an earlier study (Jensen, 1989). Food concentration for larvae was set at $200 \mathrm{mg} / \mathrm{m}^{3}$, and assuming that food concentration increased with size of walleye, the values for YOY, juveniles, and adults were set at 1000, 1500, and 2000 $\mathrm{mg} / \mathrm{m}^{3}$. The decreases in prey per walleye, as a result of feeding, were $1 \times 10^{-7} \mathrm{mg} / \mathrm{m}^{3}$ for larvae, $5.0 \times 10^{-5} \mathrm{mg} / \mathrm{m}^{3}$ for YOY, $7.5 \times 10^{-5} \mathrm{mg} / \mathrm{m}^{3}$ for juveniles, and $1 \times 10^{-4} \mathrm{mg} / \mathrm{m}^{3}$ for adults.

Initial larval abundance was set at $1 \times 10^{7}$; this value is low, and was selected so that the approach to equilibrium could be observed. Age at maturity averaged 4 years, and the number of eggs per gram of female was 74 (Eschmeyer, 1950). The oldest age attainable was set at 8 years.

For the relation between the instantaneous mortality coefficient and weight, the parameter estimates of Peterson and Wroblewski (1984) of 1.92 for the coefficient and to -0.25 for the exponent were used for adults, juveniles, and YOY, but as in Jensen (1989) a coefficient of 20 was used for larvae. In simulations where age at maturity was a function of size, the size at maturity was $1200 \mathrm{~g}$ and the variance was $100 \mathrm{~g}$.

\section{MODEL VERIFICATION AND SENSITIVITY ANALYSIS}

The simulation model was verified by comparing yields calculated with the simulation model with yields calculated with the Beverton and Holt (1957) dynamic pool model. With the simulation model yield was calculated as:

$$
Y=\sum_{i=x_{M}}^{x_{r}} F\left(N_{i} W_{i}+N_{i+1} W_{i+1}\right) / 2
$$

which is equivalent to approximation of the yield equation with the trapezoidal rule. For the Beverton and Holt (1957) model yield is:

$$
Y=F R W_{\mathrm{inf}} \sum_{n=0}^{3} \frac{U_{\mathrm{n}} \exp \left(-n K x_{\mathrm{m}}\right)}{F+M+n K}\left\{1-\exp \left[-(F+M+n K)\left(x_{v}-x_{M}\right)\right]\right\}
$$

where $U_{0}=1, U_{1}=-3, U_{2}=3, U_{3}=-1, K$ is the growth coefficient, $W_{\text {inf }}$ is the asymptotic weight, $M$ is the instantaneous natural mortality coeffi- 


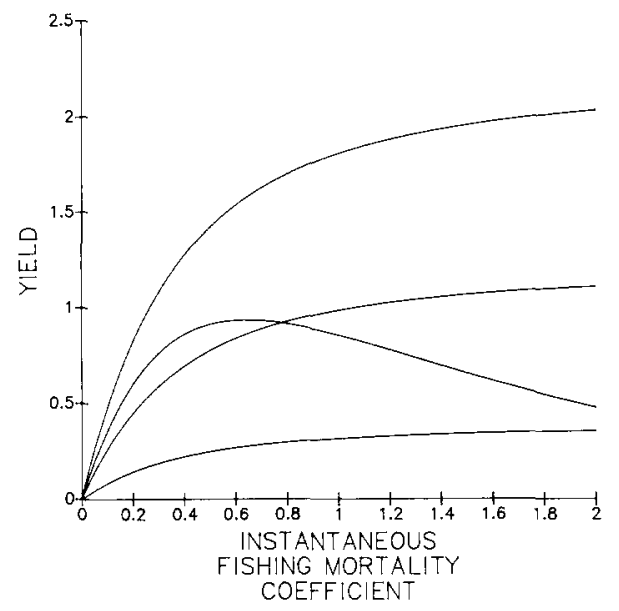

Fig. 1. Yield curves generated with the simulation model (the concaved down curve) and with the Beverton and Holt (1957) dynamic pool model (three asymptotic curves). For the middle asymptotic curve recruitment was equal to that obtained with $F=1.0$ with the simulation model, and for the bottom asymptotic curve recruitment was equal to that obtained with $F=2.0$ with the simulation model.

cient, $F$ is the instantaneous fishing mortality coefficient, $R$ is the number of recruits, $x_{M}$ is age at recruitment, and $x_{v}$ is the oldest age attainable. For the walleye population, the parameter estimates were $K=0.35$ per year, $W_{\text {inf }}=4233 \mathrm{~g}, M=0.39$ per year, $x_{M}=4$ years, and $x_{v}=8$ years (Jensen, 1989).

The shape of the yield curve for the Beverton and Holt (1957) model is different from the shape of the yield curve for the simulation model. With the simulation model, yield increased to a maximum at about $F=0.60$, and began to decrease (Fig. 1). In the simulation model increasing effort at first more than offsets the decrease in abundance resulting from the decrease in recruitment, but as effort continues to increase, the decrease in recruitment begins to outweigh the returns from an increase in effort, and further increase in fishing mortality results in a decrease in yield. In the Beverton and Holt (1957) model, when an optimum yield occurs it results from a balance of growth against mortality with recruitment constant, but for walleye there is no optimum yield; walleye natural mortality is too high.

With a constant fishing mortality the two models give similar results. The top asymptotic curve (Fig. 1) is yield calculated with the Beverton and Holt (1957) model with recruitment from the simulation model for an unexploited population. The middle asymptotic curve is yield calculated with the Beverton and Holt (1957) model with recruitment from the simulation model for a fishing mortality coefficient of 1.0. The bottom asymptotic curve is yield 


\section{TABLE 1}

Results of sensitivity analysis of model parameters

\begin{tabular}{|c|c|c|c|}
\hline \multirow[t]{2}{*}{ Parameter } & \multicolumn{3}{|l|}{ Output } \\
\hline & Recruitment & Adult abundance & Biomass \\
\hline$\vec{H}$ & 0.0865 & 0.0847 & 0.0478 \\
\hline$S$ & 0.3251 & 0.3358 & 0.4736 \\
\hline$n$ & 9.5637 & 224.0792 & 74.8418 \\
\hline$m$ & -7.9203 & -8.3568 & -9.2507 \\
\hline$C$ & 2.1649 & 2.6667 & 6.2567 \\
\hline$x_{m}$ & -2.1975 & -2.4195 & -0.0844 \\
\hline$k^{m}$ & -1.2831 & -1.6067 & -3.0372 \\
\hline$v$ & -1.0613 & -1.0504 & -0.6055 \\
\hline $\boldsymbol{W}(0)$ & 0.1872 & 0.1834 & 0.1038 \\
\hline$g$ & -0.8009 & -0.7862 & -0.4394 \\
\hline
\end{tabular}

calculated with the Beverton and Holt (1957) model with recruitment from the simulation model for a fishing mortality of 2.0. With similar recruitment levels the two models give similar yields, but the Beverton and Holt (1957) model assumes fishing has no effect on recruitment and the simulation model indicates that exploitation has a considerable effect on recruitment.

The sensitivity of simulation results to parameter values was determined by calculating sensitivities as

$T(p)=\frac{\Delta(p) O}{\Delta(O) p}$

where $\Delta(p)$ is change in a parameter value, $\Delta(O)$ is change in output, $O$ is the original output, and $p$ is the original parameter value. $T(p)=1$ indicates change in output is the same as change in input; $T(p)<1$ indicates less change in output than input, and $T(p)>1$ indicates output changes more than input. The resulting sensitivities (Table 1) indicate that the exponents $m$ and $n$ have a large effect on the results, and that the parameters $C$ and $x_{m}$ also are important. Of these, only the value of the parameter $C$ has been determined by calibration of the model to the data.

\section{SIMULATION WITH VON BERTALANFFY GROWTH EQUATION}

Simulations were done with: (a) the von Bertalanffy growth equation and age specific mortalities, (b) food limited bioenergetic growth and age-specific mortality, (c) food-limited bioenergetic growth and size specific mortality, and (d) food-limited bioenergetic growth and aged at maturity dependent on size. In simulations with the von Bertalanffy growth equation and age 
specific mortalities there was no compensation for fishing mortality and the population decreased to extinction when fished.

\section{SIMULATION WITH FOOD-LIMITED BIOENERGETIC GROWTH AND AGE- SPECIFIC MORTALITIES}

Growth of walleye has been studied extensively. Large variations in growth rates may occur between year classes and among individuals of the same year class, and an inverse relation between walleye population density and growth rate is well documented (Colby et al., 1979). One of the most important factors affecting growth of walleye is the amount of forage available (Colby et al., 1979). The relation between weight and fecundity is almost linear (Johnston, 1977).

In simulations with food-limited bioenergetic growth and constant agespecific mortalities, the population compensated for increases in mortality (Fig. 2). The simulations started at a low density and it took about 65 years to attain the carrying capacity. The rate of population increase was low.

At first, the number of spawners and recruits at equilibrium both decrease gradually with increase in fishing mortality, but then a steeper decline occurs with further increase in fishing mortality (Fig. 3). As fishing mortality increases, the population compensates with an increase in growth of individuals which increases the population's production of eggs. The importance of this mode, of compensation has been overlooked in previous studies. After maximum growth is attained, further increase in mortality cannot be offset, and both the number of spawners and the number of recruits decrease rapidly. The number of recruits decreased more slowly than the number of

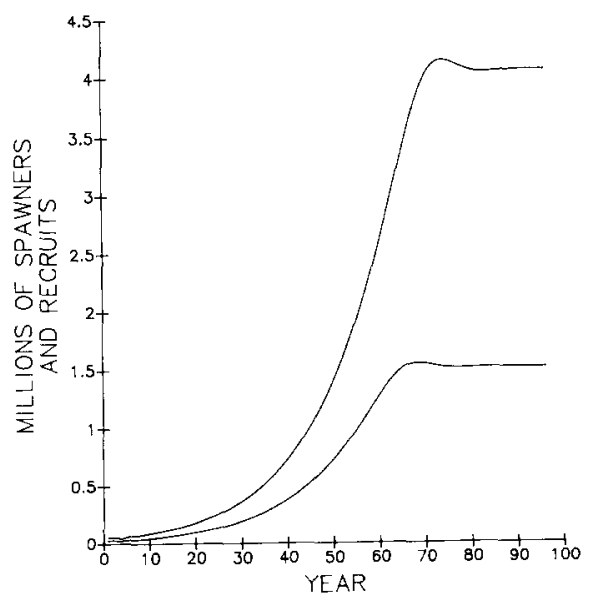

Fig. 2. Millions of spawners and recruits over time with food-limited bioenergetic growth. 


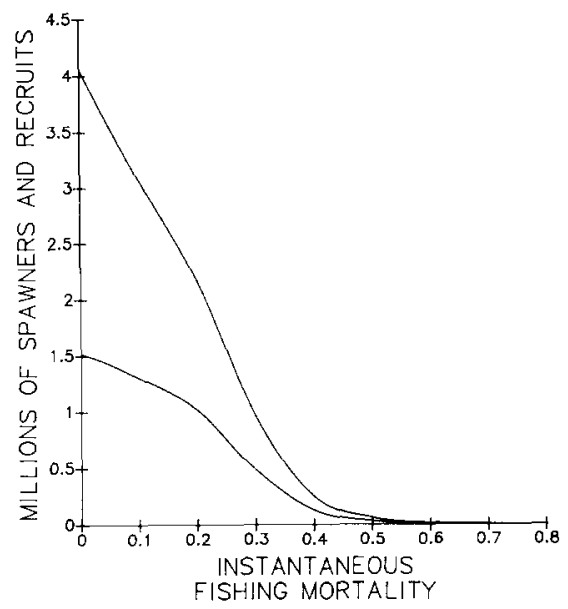

Fig. 3. Millions of spawners and recruits as a function of fishing mortality coefficient with food limited bioenergetic growth.

spawners because a rapid change in age structure of the adult population occurs-when fishing mortality increases.

As fishing mortality increased, yield increased to a maximum of 0.8 million $\mathrm{kg}$ at a fishing mortality of about 0.30 per year, and then yield decreased to zero as fishing mortality continued to increase (Fig 4A). The relation between fishing mortality and yield for the simulations is similar to the parabola obtained with the logistic surplus production model (Schaefer,
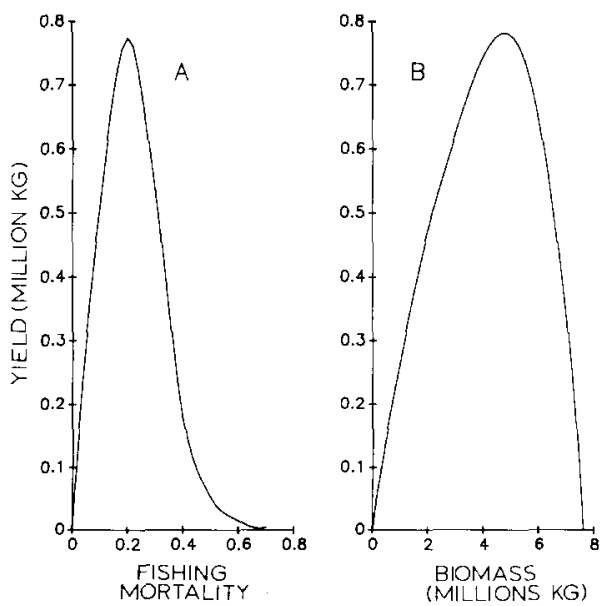

Fig. 4. (A) Relation between increase in instantaneous fishing mortality coefficient and yield with food-limited bioenergetic growth. (B) Relation between biomass and yield with foodlimited bioenergetic growth. 
1954); however, at high fishing mortalities yield decreases directly to zero with the parabola, and in the simulation model zero yield is approached asymptotically. The relation between biomass and yield given by the simulation model indicates that the maximum sustainable yield is produced at a biomass of about two-thirds of the carrying capacity (Fig. 4B), as compared to one-half the carrying capacity for the logistic surplus production model (Schaefer, 1954).

\section{SIMULATION WITH FOOD-LIMITED BIOENERGETIC GROWTH AND SIZE- SPECIFIC MORTALITIES}

Northern pike and many other species feed on walleye fry, and saugers, bullheads, burbot, and yellow perch feed on walleye YOY (Colby et al., 1979). Size specific predation could be important. In the simulation model, if mortality is dependent on size, as in the Peterson and Wroblewski (1984) equation, the capacity to compensate for fishing mortality is much increased. The population attains a carrying capacity in only 10 years with a relation between size and mortality (Fig. 5) as compared to 65 years without such a relation (Fig. 2), indicating that the resilience of a population is much higher with this additional compensation process. The population growth curves were somewhat 5-shaped, as for logistic population growth (Fig. 5); however, there were bumps and an overshoot of the carrying capacity that resulted from the reproductive time lag. Walleye mature and are recruited at age 4 , and in the simulation model it takes 4 years for changes in abundance of adults to be reflected in recruitment. The reproductive time lag does not produce lasting cycles in abundance.

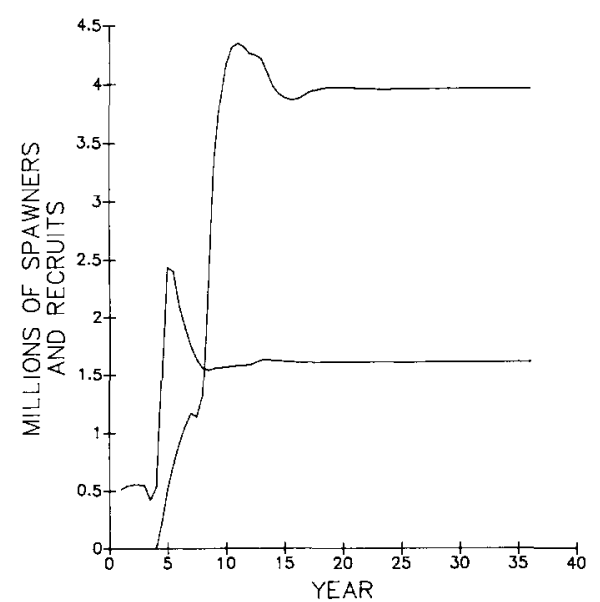

Fig. 5. Millions of spawners and recruits over time with food-limited bioenergetic growth and a dynamic size mortality relation. 

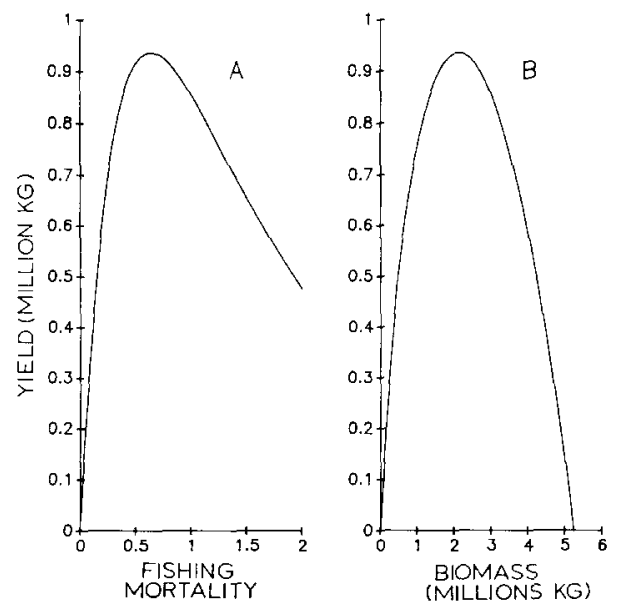

Fig. 6. (A) Relation between yield and fishing mortality with food limited bioenergetic growth and a dynamic size mortality relation. (B) Relation between yield and biomass with foodlimited growth and a dynamic size mortality relation.

The yield curve obtained with the simulation model is similar to that obtained with the Beverton and Holt (1957) model with constant recruitment, low natural mortality, and high rate of growth (Fig. 6A). As fishing mortality increases, yield increases to a maximum of about 0.95 million $\mathrm{kg}$ at a fishing mortality of 0.65 per year, and then yield begins to decrease gradually with further increase in fishing mortality. Yield does not decrease to zero even with a high fishing mortality. The maximum sustainable yield is

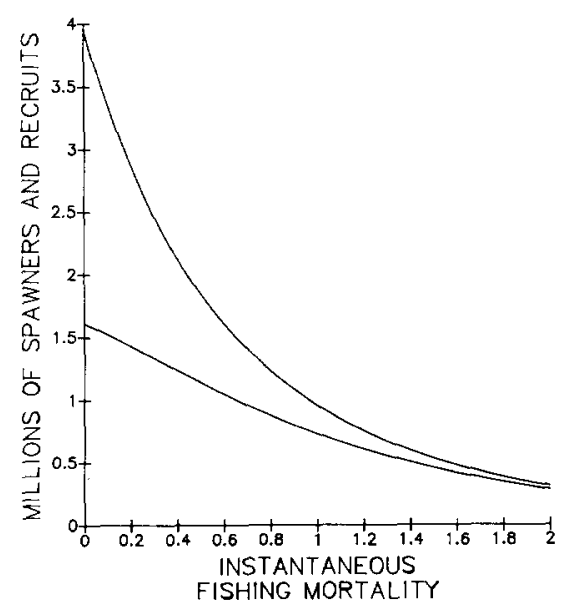

Fig. 7. Millions of spawners and recruits as a function of fishing mortality with food-limited bioenergetic growth and a dynamic size mortality relation. 


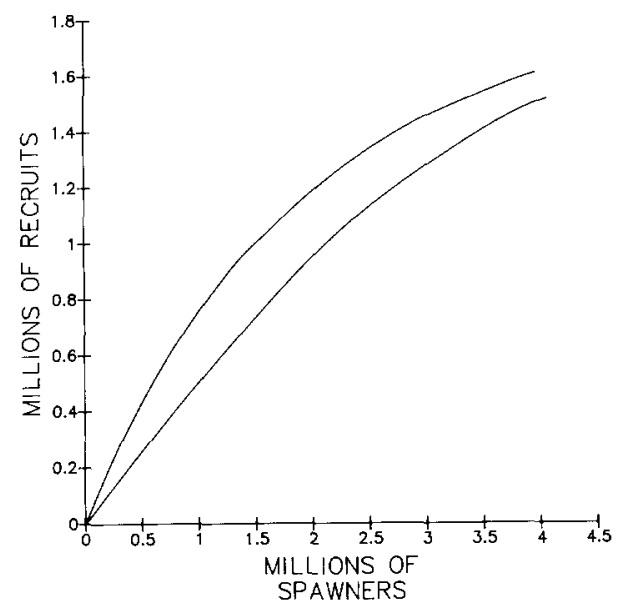

Fig. 8. Association between spawners and recruits with food-limited bioenergetic growth with (top) and without (bottom) dynamic size mortality relation.

obtained at a biomass of slightly less than one-half the carrying capacity (Fig. 6B).

As fishing mortality increases, both the number of spawners and the number of recruits decrease exponentially (Fig. 7); the population becomes dominated entirely by new recruits when fishing mortality is high, and it is these new recruits that sustain the fishery.

The number of recruits is not determined by the number of spawners, but the association between spawners and recruits can be determined (Fig. 8), and it is similar to that given by Beverton and Holt (1957). This also is the relation that Ricker (1975) assumed would occur with food limited growth. In the simulations the spawner-recruit relation is not a cause and effect relation; the number of spawners does not determine the number of recruits. The spawner-recruit relation does not provide population regulation in the computer model, and the compensation process, which is food limited growth, determines both the number of spawners and the number of recruits.

SIMULATION WITH FOOD-LIMITED BIOENERGETIC GROWTH AND AGE AT MATURITY A FUNCTION OF SIZE

Age at maturity varies considerably among walleye stocks and it is generally inversely related to growth rate, which in turn is affected by the amount of food available (Colby et al., 1979). Northern stocks mature later and over a larger number of years than southern stocks and heavily exploited stocks (Colby et al., 1979). A trend towards earlier maturity among 

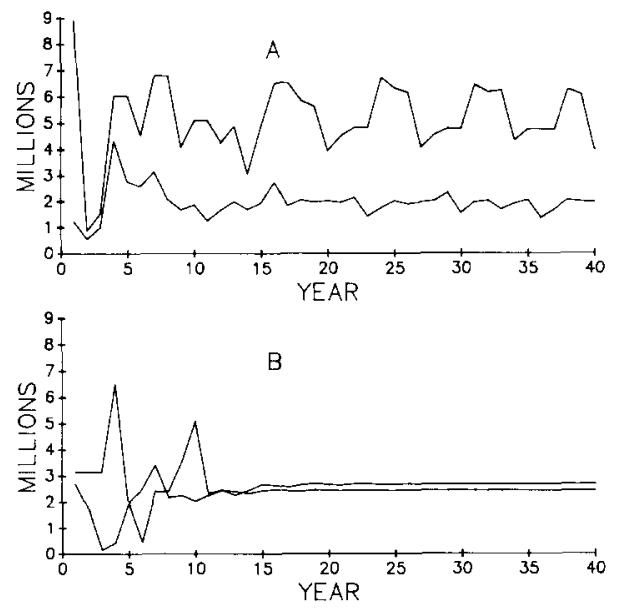

Fig. 9. (A) Millions of spawners and recruits with food-limited bioenergetic growth, age at maturity a function of size, and a low fishing mortality. (B) Millions of spawners and recruits with food limited bioenergetic growth, age at maturity a function of size, and a high fishing mortality.

more rapidly growing fish has been reported in Oneida Lake, New York, and a similar trend was observed for heavily exploited stocks in Saginaw Bay, the western basin of Lake Erie, and Dexter Lake, Ontario (Colby et al., 1979). In Lake Erie the percent of walleye maturing at age 3 increased from 40 to 80 during a period when the stock size declined markedly (Shuter and Koonce, 1977). Age and size at maturity within a given population vary with food availability (Colby et al., 1979).

With age at maturity a function of size, the simulation model indicates that there is a high capacity to increase, similar to that with size specific mortality. If fishing mortality is low, population size fluctuates (Fig. 9A). If fishing mortality is high, the fluctuations in abundance disappear (Fig. 9B). The fluctuations are caused by changes in age at maturity which produce large changes in recruitment and abundance. The proportion of each age group spawning was determined by the number larger than weight at maturity at spawning using the logistic distribution to describe the weights at age. As the growth rate changed the numbers added to or removed from the adult population changed gradually.

The relation between yield and fishing mortality is similar to the relation obtained with food-limited bioenergetic growth and size-specific mortality (Fig. 10). Yield is slightly higher with age at maturity a function of size.

With age at maturity a function of size the number of spawners and recruits did not decrease smoothly as fishing mortality increased (Fig. 11). When age at maturity begins to decrease there is a large increase in the 


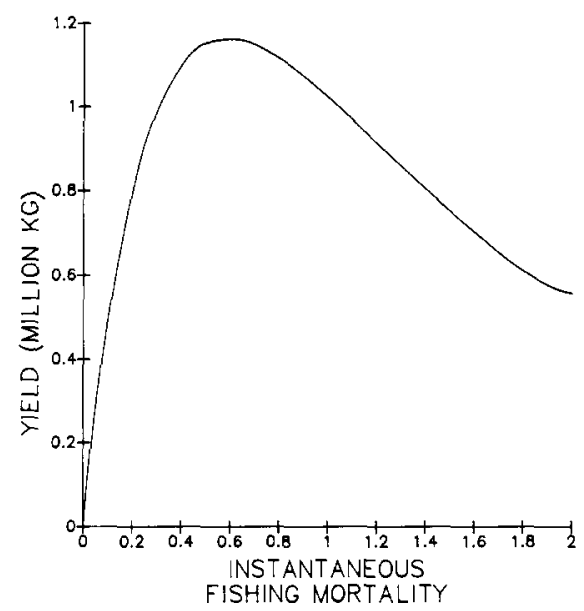

Fig. 10. Relation between yield and fishing mortality with food-limited bioenergetic growth and age at maturity a function of size.

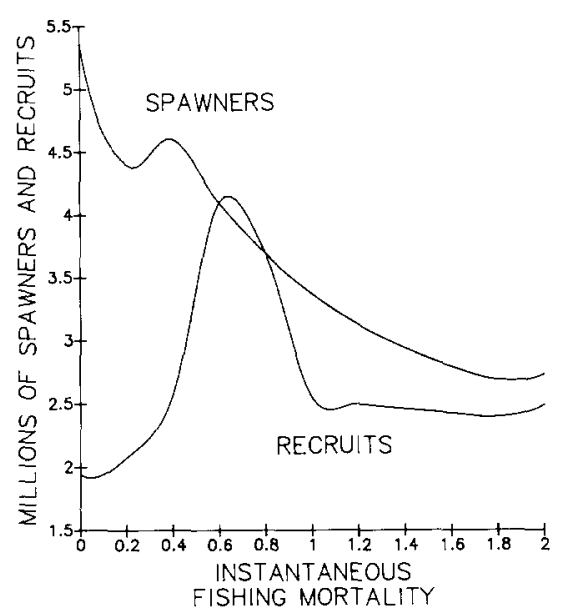

Fig. 11. Millions of spawners and recruits as a function of fishing mortality with food limited bioenergetic growth and age at maturity a function of size.

number of recruits due to the large number of individuals in younger age groups.

\section{GENERAL DISCUSSION}

The simulations have applied processes proposed for fish population regulation to show that these processes could adjust population size to a new stable level when fishing mortality increases. Data available for verification 
of the processes and for estimation of parameters are limited, but there are extensive life history data that suggest the processes and parameter estimates used in the simulation model are reasonable. Forney (1977) hypothesized that walleye were regulated by biological factors; the concurrent responses of growth and recruitment to variation in prey abundance. Strong year classes developed in years when growth was rapid because of high prey density, which enhanced growth and reduced mortality (Chevalier, 1977; Forney, 1977).

Population processes are difficult to fully document in the laboratory because population densities in laboratory studies are many times higher than in the field, and laboratory environments do not have the complexity of natural environments. Confirmation in the field also is difficult. A large number of interrelated factors operate, spatial and temporal variation are high, and a single observation per year is obtainable for recruitment. For fishes, processes that operate on early life stages are most important, and data for early life stages are highly variable, and difficult to obtain. Small changes in larval survival rates, changes that are impossible to detect, are biologically significant. This has led to nonconclusive results in field studies (e.g., Serns, 1982, 1984).

Mathematical models and computer simulations are of some help in this situation. The processes hypothesized for population regulation can be quantified in mathematical models, and the models can be applied to determine the potential for compensation provided by the processes and to determine changes in life history variables that are necessary for population regulation to occur, and that need to be detected in the field.

\section{REFERENCES}

Beverton, R.J.H. and Holt, S.J., 1957. On the dynamics of exploited fish populations. U.K. Min. Agric. Fish., Fish. Invest. (Ser. 2) 19, 533 pp.

Chevalier, J.R., 1977. Changes in walleye (Stizostedion vitreum vitreum) population in Rainy Lake and factors in abundance, 1924-75. J. Fish. Res. Board Can., 34: 1696-1702.

Colby, P.J., McNicol, R.E. and Ryder, R.A., 1979. Synopsis of biological data on the walleye Stizostedion v. vitreum (Mitchell 1818). FAO Fisheries Synopsis, 119. Food and Agriculture Organization, Rome, $139 \mathrm{pp}$.

Cushing, D.H., 1975. Marine Ecology and Fisheries. Cambridge University, London, 278 pp.

Dahlgren, B.T., 1980. The effects of population density on fecundity and fertility in the guppy, Poecilia reticulata (Peters). J. Fish. Biol., 15: 71-91.

Eschmeyer, P.H., 1950. The life history of the walleye (Stizostedion vitreum vitreum) in Michigan. Bull. 3, Michigan Department of Conservation, Ann Arbor, MI.

Forney, J.L., 1977. Evidence of inter- and intraspecific competition as factors regulating walleye (Stizostedion vitreum vitreum) biomass in Oneida Lake, New York. J. Fish. Res. Board Can., 34: 1812-1820.

Hankin, D.G., 1980. A multistage recruitment process in laboratory fish populations: implications for models of fish population dynamics. Fish. Bull., 78: 555-578. 
Healey, M.C., 1980. Growth and recruitment in experimentally exploited lake whitefish (Coregonus clupeaformis) populations. J. Fish. Res. Board Can., 37: 244-267.

Hjort, J., 1914. Fluctuations in the great fisheries of northern Europe viewed in the light of biological research. Rapp. P.-V. Reun. Cons. Int. Explor. Mer, 20: 1-228.

Ivlev, V.S., 1961. Experimental ecology of the feeding of fishes (Translated form the Russian by Douglas Scott). Yale University Press. New Haven, CT, 302 pp.

Jensen, A.L., 1971. Response of brook trout (Salvelinus fontinalis) populations to a fishery. J. Fish. Res. Board Can., 28: 458-460.

Jensen, A.L., 1981. Population regulation in lake whitefish (Coregonus clupeaformis). J. Fish. Biol., 19: 557-573.

Jensen, A.L., 1989. Simulation of the potential for life history components to regulate walleye population size. Ecol. Modelling, 45: 27-4l.

Johnston, D.A., 1977. Population dynamics of walleye (Stiozostedion vitreum vitreum) and yellow perch (Perca flavescens) in Lake St. Clair, especially during 1970-76. J. Fish. Res. Board Can., 34: 1869-1877.

Larkin, P.A., 1956. Interspecific competition and population control in freshwater fish. J. Fish. Res. Board Can., 13: 327-342.

Muth, K.M. and Wolfert, D.R., 1986. Changes in growth and maturity of walleyes associated with stock rehabilitation in western Lake Erie, 1964-1983. North Am. J. Fish. Manage., 6: $168-175$.

Peterson, I. and Wroblewski, J.S., 1984. Mortality rates of fishes in the pelagic ecosystem. Can. J. Fish. Aquat. Sci. 41: 1117-1120.

Ricker, W.E., 1975. Computation and interpretation of biological statistics of fish populations. Bull. 191, Fisheries Research Board of Canada, Ottawa, Ont., 382 pp.

Rothschild, B.J., 1986. Dynamics of marine fish populations. Harvard University Press, Cambridge, MA, 277 pp.

Saila, S.B., Chen, X., Erzini, K. and Martin, B., 1987. Compensatory mechanisms in fish populations: Literature reviews, 1. Critical evaluation of case histories of fish populations experiencing chronic exploitation or impact. EA-5200, Electric Power Research Institute, Palo Alto, CA, 300 pp.

Schaefer, M.B., 1954. Some aspects of the dynamics of populations important to the managment of commerical marine fisheries. Inter-Amer. Trop. Tuna Comm. Bull., 1: $27-56$.

Serns, S.L., 1982. Influence of various factors on density and growth of age-0 walleyes in Escanaba Lake, Wisconsin, 1958-1980. Trans. Am. Fish. Soc., 111: 299-306.

Serns, S.L., 1984. Walleye growth in relation to water temperature, food availability, and population density in Escanaba Lake, 1956-1982. Res. Rep. 130, Wisconsin Department of Natural Resources, Madison, WI.

Shuter, B.J. and Koonce, J.E., 1977. A dynamic model of the western Lake Erie walleye (Stizostedion vitreum vitreum) population. J. Fish. Res. Board Can., 34: 1972-1982.

Silliman, R.P., 1968. Interaction of food level and exploitation in experimental fish populations. Fish. Bull., 66: 425-439.

Silliman, R.P., 1971. Effect of crowding on relation between exploitation and yield in Tilapia macrocephala. Fish. Bull., 70: 693-698.

Silliman, R.P. and Gutsell, J.S., 1958. Experimental exploitation of fish populations. Fish. Bull., 58: 214-252.

Ursin, E., 1967. A mathematical model of some aspects of fish growth, respiration, end mortality. J. Fish. Res. Board Can., 24: 2355-2390.

Ursin, E., 1979. Principles of growth in fishes. Symp. Zool. Soc. London, 44: 63-87.

Winberg, G.G., 1956. Rate of metabolism and food requirements in fishes. Translation Series 194, 1960. Fisheries Research Board of Canada, Ottawa, Ont., 201 pp. 